\title{
SMURF1 silencing diminishes a CD44-high cancer stem cell-like population in head and neck squamous cell carcinoma
}

\author{
Ali Khammanivong ${ }^{1}$, Raj Gopalakrishnan ${ }^{2,3}$ and Erin B Dickerson ${ }^{1,3^{*}}$
}

\begin{abstract}
Background: Bone morphogenetic protein (BMP) signaling is thought to play key roles in regulating the survival and maintenance of cancer stem cells (CSCs), which contribute to disease recurrences and treatment failures in many malignances, including head and neck squamous cell carcinoma (HNSCC). Intracellular BMP signaling is regulated by SMAD specific E3 ubiquitin protein ligase 1 (SMURF1) during cellular development. However, little is known about the role or regulation of BMP signaling in HNSCC CSCS.

Methods: Two CSC-like populations, CD44 ${ }^{\text {high }} / \mathrm{BM} 11^{\text {high }}$ and CD44 $4^{\text {high }} / \mathrm{ALDH} \mathrm{H}^{\text {high }}$, were enriched from HNSCC cell lines and evaluated for the expression of SMURF1 by qRT-PCR, flow cytometry, and immunoblotting. The activation status of BMP signaling in these populations was determined by using immunoblotting to detect phosphorylated SMAD1/5/8 (pSMAD1/5/8) levels. Knockdown of SMURF1 transcripts by RNA interference was used to assess the role of SMURF1 in BMP signaling and CSC maintenance. Loss of CSC-like phenotypes following SMURF1 knockdown was determined by changes in CD44 ${ }^{\text {high }}$ levels, cellular differentiation, and reduction in colony formation.

Results: Populations of enriched CSC-like cells displayed decreased levels of PSMAD1/5/8 and BMP signaling target gene ID1 while SMURF1, CD44, and BMI1 were highly expressed when compared to non-CSC populations. Stable knockdown of SMURF1 expression in CSC-like cells increased pSMAD1/5/8 protein levels, indicating the reactivation of BMP signaling pathways. Decreased expression of SMURF1 also promoted adipogenic differentiation and reduced colony formation in a three-dimensional culture assay, indicating loss of tumorigenic capacity. The role of SMURF1 and inhibition of BMP signaling in maintaining a CSC-like population was confirmed by the loss of a CD44 high expressing subpopulation in SMURF1 knockdown cells.
\end{abstract}

Conclusions: Our findings suggest that inhibition of BMP signaling potentiates the long-term survival of HNSCC CSCS, and that this inhibition is mediated by SMURF1. Targeting SMURF1 and restoring BMP signaling may offer a new therapeutic approach to promote differentiation and reduction of CSC populations leading to reduced drug resistance and disease recurrence.

Keywords: BMP signaling, SMURF1, Cancer stem cell, HNSCC, CD44, pSMAD1/5/8

\footnotetext{
*Correspondence: edickers@umn.edu

'Department of Veterinary Clinical Sciences, College of Veterinary Medicine,

University of Minnesota, 1352 Boyd Avenue, Saint Paul, MN 55108, USA

${ }^{3}$ Masonic Cancer Center, University of Minnesota, 425 East River Parkway,

Minneapolis, MN 55455, USA

Full list of author information is available at the end of the article
}

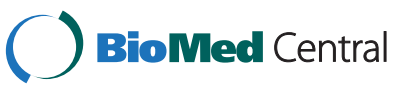

(c) 2014 Khammanivong et al.; licensee BioMed Central Ltd. This is an Open Access article distributed under the terms of the Creative Commons Attribution License (http://creativecommons.org/licenses/by/4.0), which permits unrestricted use, distribution, and reproduction in any medium, provided the original work is properly credited. The Creative Commons Public Domain Dedication waiver (http://creativecommons.org/publicdomain/zero/1.0/) applies to the data made available in this article, unless otherwise stated. 


\section{Background}

Head and neck squamous cell carcinoma (HNSCC) is among the most prevalent cancers worldwide, with approximately 500,000 incidences per year, including close to 40,000 new cases in the United States [1-3]. Despite the successes of standard treatment modalities such as surgery, radiation, and chemotherapies for the majority of patients with early stage disease [4,5], patients with regional and distant metastases or recurrent disease make up a substantial proportion of the treatment failures $[2,3,6]$, bringing the 5-year survival rate to under 50\%. Thus, the development of chemoresistance and metastatic disease remains a continuing challenge for HNSCC patients, and overcoming these obstacles requires an improved understanding of the underlying mechanisms contributing to tumorigenesis and drug resistance.

Evidence suggests that a subpopulation of cells, known as cancer stem cells (CSCs), possess the potential for self-renewal, multipotent differentiation, and tumorigenesis $[5,7,8]$, and these cells may contribute to the aggression and dismal prognosis of HNSCC. Although chemo- and radiotherapy eliminate many of the bulk tumor cells, CSCs possess traits that allow them to survive and repopulate. The surviving cells can then regenerate tumors leading to disease recurrences that are less responsive to conventional therapies. In HNSCC, CSC populations were first identified using the cell surface marker CD44 [9]. A subset of CD $44^{\text {high }}$ expressing cells was shown to possess stem cell properties along with the ability to initiate tumorigenesis in mice compared to CD44 ${ }^{\text {low/- }}$ cells [9-11]. Aldehyde dehydrogenase (ALDH) activity also has been used to identify CSCs in HNSCC [12-14]. ALDH activity correlates strongly with increased resistance to chemo- and radiotherapy $[15,16]$, and the combination of ALDH activity with CD44 expression is more selective for CSC-like populations than either marker alone [17-20].

While it is established that the implantation of extremely small numbers of ALDH ${ }^{\text {high }} / \mathrm{CD} 44^{\text {high }}$ cells consistently give rise to tumors in vivo further solidifying their tumorigenic properties [19,21], it remains relatively unclear how the expression of ALDH and CD44 are regulated in these populations. For ALDH, the epithelial-tomesenchymal transition regulator Snail was found to be a key factor in maintaining the CSC properties in HNSCC. Knockdown of Snail decreased ALDH expression, inhibited CSC-like properties, and attenuated tumorigenesis in $\mathrm{ALDH}^{\text {high }} / \mathrm{CD} 44^{\text {high }}$ cells [12]. While factors regulating CD44 expression in HNSCC are unknown, clues may come from studies in chondrocytes where co-immunoprecipitation experiments identified the interaction of SMAD1 with CD44. The interaction of SMAD1 with CD44 provides a link between CD44 and the bone morphogenetic (BMP) signaling cascade, which signals through a family of SMAD proteins [22]. The SMAD1/CD44 interaction appears to sequester SMAD1 in the cytoplasm, but the nuclear accumulation of SMAD1 increases upon BMP7 stimulation [23]. The SMAD1/CD44 interaction also is associated with reversible dormancy of CSCs along with the potential for tumor recurrence and metastasis in prostate cancer [24]. Thus, BMP signaling through SMAD proteins may be important for regulating and maintaining HNSCC $\mathrm{CSCs}$ and in the overall regulation of CD44 expression and signaling.

BMPs are members of the transforming growth factor beta (TGF- $\beta$ ) superfamily with diverse biological functions, including regulation of embryogenesis, cell proliferation, migration, differentiation, and apoptosis [25-28]. Extracellular regulation of BMP signaling is tightly regulated by factors such as noggin (NOG), chordin (CHRD), and twisted gastrulation BMP signaling modulator 1 (TWSG1) $[29,30]$. Intracellular regulation is primarily mediated by SMAD-specific E3 ubiquitin ligase 1 (SMURF1) through its interactions with SMADs. Recently, ubiquitin ligases have emerged as critical regulators for the development and function of stem cell and stem cell-like populations. For example, the E3 ligases Itch and c-Cbl have been identified as regulators of hematopoietic stem cell homeostasis and function [31,32]. In glioblastoma, two isoforms of the protein Numb differentially interacted with the $\mathrm{SCF}^{\mathrm{Fbw} 7}$ ubiquitin ligase assembly to regulate the glioblastoma cancer stem cell hierarchy [33]. Based on these findings, it is likely that other E3 ligases play similar roles in other cancers. This prompted us to investigate the role of SMURF1 in the regulation of BMP signaling and in the maintenance of HNSCC CSCs.

In this study, we investigated whether the E3 ligase SMURF1 is involved in regulating BMP signaling and the maintenance of CD44 $4^{\text {high }}$ cells in head and neck cancer cell lines. We demonstrated that cell lines grown under non-adherent culture conditions or isolated from $\mathrm{ALDH}^{\text {high }} / \mathrm{CD} 44^{\text {high }}$ populations showed inhibition of BMP signaling. Silencing of SMURF1 expression increased BMP signaling and reduced the abundance of the CD $44^{\text {high }}$ population in HNSCC cell lines. The inverse relationship between SMURF1 expression and BMP signaling indicates that BMP signaling may be important in regulating CD44 expression and, in turn, regulating CSC populations in HNSCC. Reducing SMURF1 activity to enhance BMP signaling may limit CSC function in HNSCC and provide new therapeutic approaches for reducing drug resistant populations.

\section{Results}

\section{Sphere cells generated from HNSCC cell lines show} CSC-like characteristics

To study the role of BMP signaling in modulating CSC populations, we established stable sphere cultures to enrich for CSC-like cells from three HNSCC cell lines, 
TR146, SCC-58, and UMSCC-17B. These lines were chosen for their ability to form spheres, along with longterm survival and sphere regeneration following multiple passages in cell culture (Figure 1A). Sphere formation in serum-free suspension cultures has been well established as a means to enrich for cells with CSC-like properties, including drug resistance, self-renewal capability, high expression of stem cell markers (e.g., CD44, ALDH and BMI1), tumor initiation, and differentiation capacity [10,34-36].

To establish our system, we first sought to demonstrate that sphere cells derived from the three cell lines
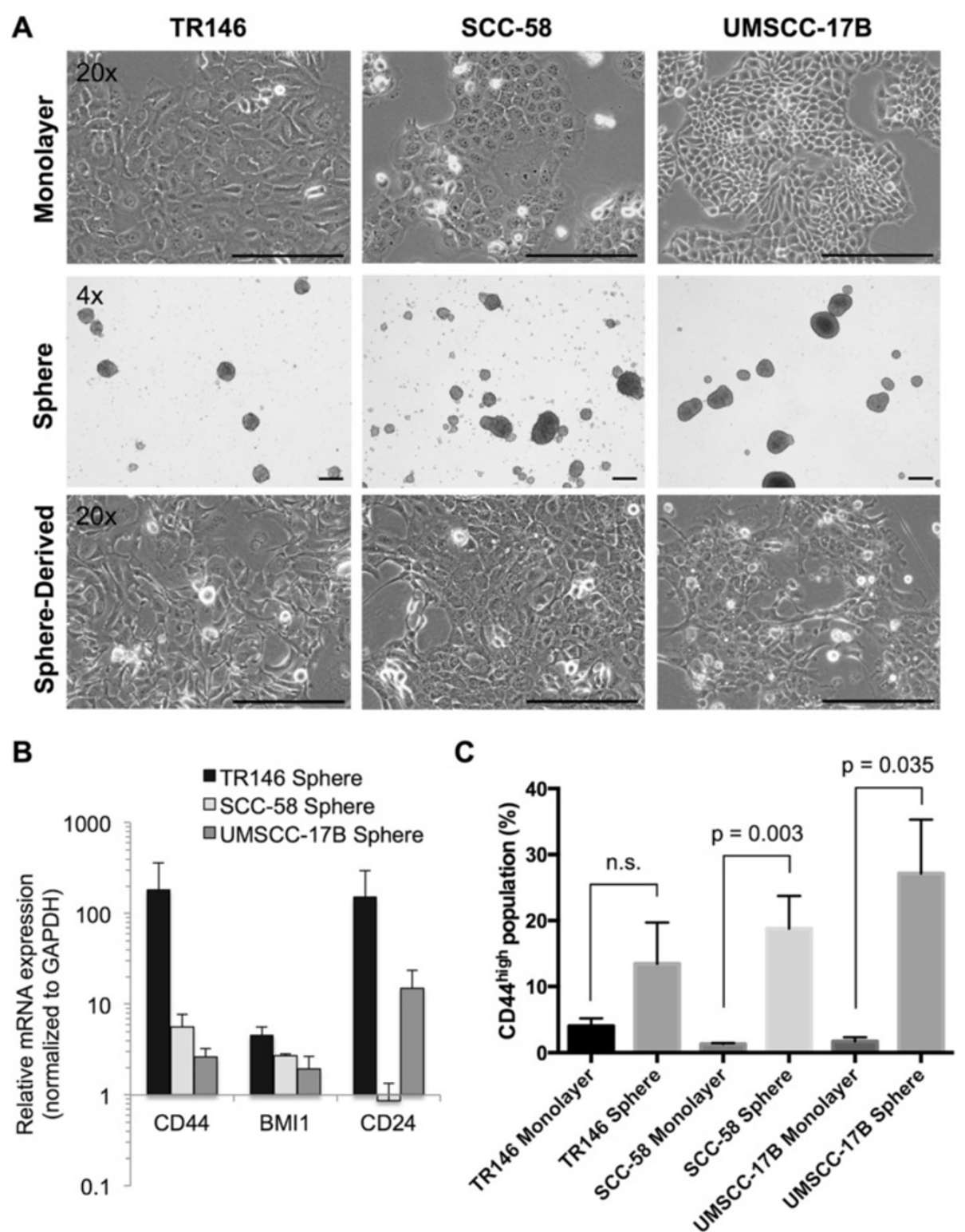

Figure 1 Sphere cells from HNSCC cell lines show CSC-like characteristics. (A) HNSCC cell lines grown as monolayers with 10\% FBS under standard adherent growth conditions (top), as spheres in serum-free suspension growth conditions (middle), and as sphere-derived cells (SDCs) under adherent growth conditions in the presence of 10\% FBS and $75 \mu \mathrm{g} / \mathrm{mL}$ Matrigel (bottom). Images were taken using phase contrast microscopy at 20x objective for monolayer and SDCs, 4x for sphere cultures. Scale bars represent $100 \mu \mathrm{m}$ in length. (B) Expression of CSC markers CD44 and BMI1 and differentiation marker CD24 in sphere cells relative to monolayer cultures by qRT-PCR. Expression was normalized to the GAPDH housekeeping gene as an internal control and shown as mean fold change \pm SE $(n \geq 3)$. (C) Summary of flow cytometry analysis of CD44 surface protein expression showing the percentages of the CD44 high populations in monolayer and sphere cells from TR146 $(n=8)$, SCC $-58(n=8)$ and UMSCC-17B $(n=3)$. Representative flow cytometry data showing the gating of the CD44 ${ }^{\text {high }}$ cells are shown in Additional file 1: Figure S1. Data are presented as mean \pm SE for the indicated total number of independent experiments. Statistical analysis was performed using two-tailed Student's $t$-test with equal variance. n.s. $=$ not significant $(p>0.05)$. 
possessed properties previously attributed to HNSCC CSCs. To do this, we utilized single cell suspensions of sphere cells or sphere cells that were able to re-establish adherent monolayer cultures in the presence of Matrigel, generating populations of sphere-derived cells or SDCs. CSC-like cells grown as spheres in culture are highly quiescent and divide slowly, limiting cell numbers and analysis, so we used SDCs in some studies to partially circumvent this issue. Sphere cells or SDCs grown for 18-24 hours on Matrigel showed increased expression of CD44 and BMI1 (Figure 1B) along with an increase in the percentage of cells in the $\mathrm{CD} 44^{\text {high }}$ population (Figure 1C). BMI1 and CD44 $4^{\text {high }}$ are two reported markers for HNSCC CSCs $[9,37,38]$. Representative flow cytometry analysis of how the $\mathrm{CD} 44^{\text {high }}$ populations were measured in each cell line is shown in supplementary Additional file 1: Figure S1. CD24 expression, reported to be variable in HNSCC CSCs [39], was upregulated in TR146 and UMSCC-17B sphere cells (Figure 1B), but its expression remained unchanged in SCC-58 sphere cells. Sphere cells were highly resistant to cisplatin compared to their monolayer cultures (Additional file 2: Figure S2), and ALDH activity was either unchanged or slightly reduced when compared to those from cells grown as adherent monolayers (data not shown). Because CD44 and BMI1 expression were consistently expressed in sphere cells and SDCs from the three cell lines, sphere cells grown under nonadherent conditions for 10 to 14 days were used as representative CSC-like populations, and all SDCs were derived from these populations for the remaining studies.

\section{BMP signaling and SMURF1 are differentially regulated in sphere cells}

To determine if BMP signaling pathways were differentially regulated in sphere versus monolayer cells, we compared the gene expression profiles of BMP signaling molecules using qRT-PCR arrays. The BMP signaling inhibitors SMURF1, BMPER, and BAMBI were upregulated in all sphere cell populations while the BMP signaling target genes ID1 and ID2 were downregulated (Figure 2A). However, BMPER and ID2 expression was not consistent and varied between the three cell lines. Because SMURF1 has been shown to inhibit mesenchymal stem cell proliferation and differentiation [40] and to promote invasiveness and CSC properties in pancreatic cancer [41], we chose to validate its expression at the protein level and determine if BMP signaling was inhibited in the sphere cells. We confirmed that SMURF1 protein expression was increased in sphere cells grown in cell culture for 7 days when compared to SMURF1 levels in monolayer cells, and that this increase persisted in sphere cells through day 14 (Figure 2B). SMURF1 expression in monolayer cells was low or not detected. We then measured phosphorylated SMAD1, 5 and 8 (pSMAD1/5/8) levels to determine the status of BMP signaling in the sphere cells. Phosphorylated SMAD1/5/8 proteins are indicative of active BMP signaling; therefore decreased pSMAD1/5/8 levels indicate inhibition of this signaling pathway. Using immunoblotting, we determined that the pSMAD1/5/8 levels in spheres were greatly reduced when compared to those of cultured monolayer cells (Figure 2C), suggesting that BMP signaling was inhibited in sphere cells but active in monolayers. Reduced BMP signaling appeared to be specific for the canonical BMP signaling pathway since phosphorylated p38 MAPK levels, a downstream marker of non-canonical BMP signaling, did not differ between the sphere and monolayer cell populations (data not shown).

Because the reduced levels of pSMAD1/5/8 could be attributed to a loss or reduction of BMP receptor ligand expression rather than inhibition of the pathway by SMURF1, we measured BMP2, 4, and 7 expression by qRT-PCR and secretion of BMP2 by ELISA (Additional file 3: Figure S3). These BMPs activate the BMP signaling pathway by increasing pSMAD1/5/8 phosphorylation critical for cellular growth and differentiation $[25,42,43]$. The sphere cells showed increased expression of BMP2 and BMP7 at the mRNA level (Additional file 3: Figure S3A), and BMP2 levels in the supernatants from sphere cells were higher than levels found in the cell culture supernatants from the monolayer cells (Additional file 3: Figure S3B). While levels of BMP2 production by the sphere cells decreased over a 14-day period, BMP2 levels remained higher, in general, than those found in the monolayer cell culture supernatants. Taken together, our results indicate that BMP signaling is reduced in sphere cells, and that this process is regulated, at least in part, by SMURF1. The insensitivity to the presence of BMP ligands provides evidence for CSC-like maintenance through BMP signaling inhibition, while increased BMP2 production likely indicates a paracrine growth promoting function of these cells.

\section{BMP signaling is decreased in CD44 $4^{\text {high }} / \mathrm{ALDH}^{\text {high }}$ populations}

We next examined pSMAD1/5/8 levels in CD $44^{\text {high }}$ / $\mathrm{ALDH}^{\text {high }}$ cell populations to assess the activation status of BMP signaling since $\mathrm{CD} 44^{\text {high }} / \mathrm{ALDH}^{\text {high }}$ cell populations have been shown to represent CSC-like populations in HNSCC and are highly tumorigenic in vivo $[14,20]$. In addition, confirmation of decreased pSMAD1/5/8 levels in the $\mathrm{CD} 44^{\text {high }} / \mathrm{ALDH}{ }^{\text {high }}$ cells would further support the use of our sphere cell system to study the mechanism behind SMURF1 regulation of BMP signaling in HNSCC CSCs. TR146 and SCC-58 cells were cultured in standard monolayer conditions and stained for ALDH activity followed by CD44 cell surface immunostaining. Double stained cells were sorted based on the CD $44^{\text {high }} / \mathrm{ALDH}^{\text {high }}$ 

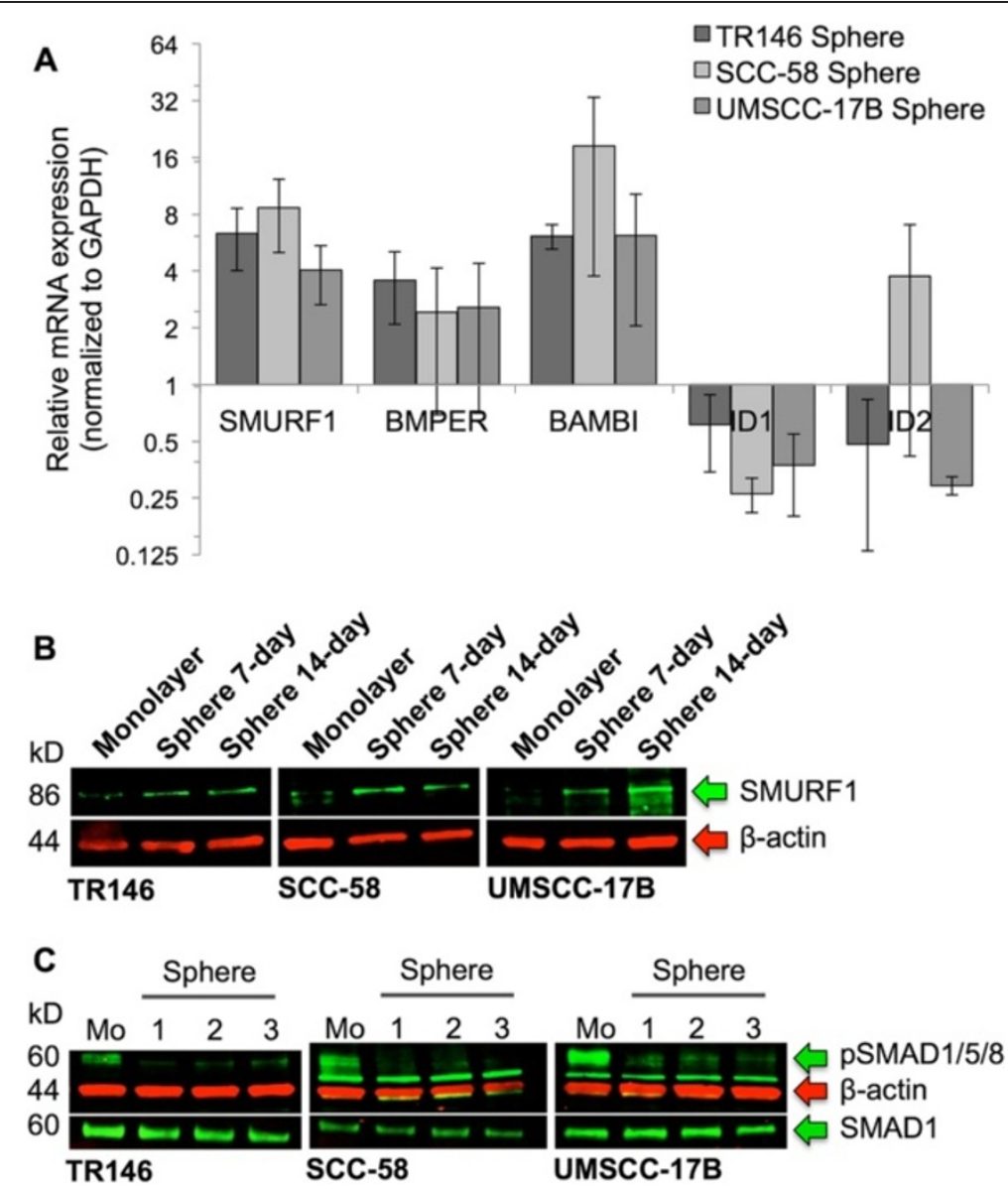

Figure 2 BMP signaling and SMURF1 are differentially regulated in HNSCC CSC-like sphere cells. (A) Summary of qRT-PCR array data showing relative expression of BMP signaling inhibitors (SMURF1, BMPER, and BAMBI) and BMP signaling target genes ID1 and ID2 in sphere cell cultures compared to the monolayer cell cultures. Data are shown as mean \pm SE with $n \geq 3$. (B) Immunoblotting of SMURF1 in monolayer cells and spheres cells from 7-day and 14-day sphere cell culture, shown as a representative of at least three independent repeats. (C) Immunoblotting of pSMAD1/5/8 and total SMAD1 in monolayer (Mo) and three independent, 14-day sphere cultures. $\beta$-actin was used as total protein loading control for all samples.

and $\mathrm{CD} 44^{\text {low }} / \mathrm{ALDH}^{\text {low }}$ markers (Figure $3 \mathrm{~A}$ and $\mathrm{B}$ ). The CD $44^{\text {high }} / \mathrm{ALDH}^{\text {high }}$ cells showed increased SMURF1 protein levels while pSMAD1/5/8 protein levels were reduced compared to the CD $44^{\text {low }} / \mathrm{ALDH}^{\text {low }}$ and CD $44^{\text {depleted/ }}$ $\mathrm{ALDH}^{\text {low }}$ (cells further depleted for CD44) populations (Figure 3C and D). SMAD1 expression levels were unchanged. These results suggest that BMP signaling is regulated in a manner similar to that observed in the sphere cell populations. We then asked if CD44 $4^{\text {high }}$ expression alone can serve as a marker for CSC-like cells in our study by performing a correlation analysis between CD44 and SMURF1. As expected, SMURF1 was highly associated with CD44 surface expression (Figure 4A). Flow cytometry analysis further indicated that SMURF1 expression was higher in CD $44^{\text {high }}$ than in CD $44^{\text {low }}$ cell populations (Figure $4 \mathrm{~B}$ and $\mathrm{C}$ ), demonstrating that higher SMURF1 levels are associated with cells reported to possess CSC-like properties. Based on these results, we sought to further define the role of SMURF1 in regulating BMP signaling.

\section{SMURF1 knockdown reactivates BMP signaling in CSC-like HNSCC cells}

Our data suggested that SMURF1 plays a role in the suppression of BMP signaling to maintain the CSC-like population. Although extracellular inhibitors may contribute to this inhibition, SMURF1 directly inhibits the activation of SMAD1, 5, and 8 and blocks the downstream BMP signaling cascade $[44,45]$. To confirm this finding, we performed an expression knockdown study of SMURF1 using RNA interference. We transduced the monolayer cultures with either SMURF1 shRNA lentivirus (shSMURF1) or non-targeting shRNA (shNeg) with high efficiency ( 90\%) before placing the cells into cell 


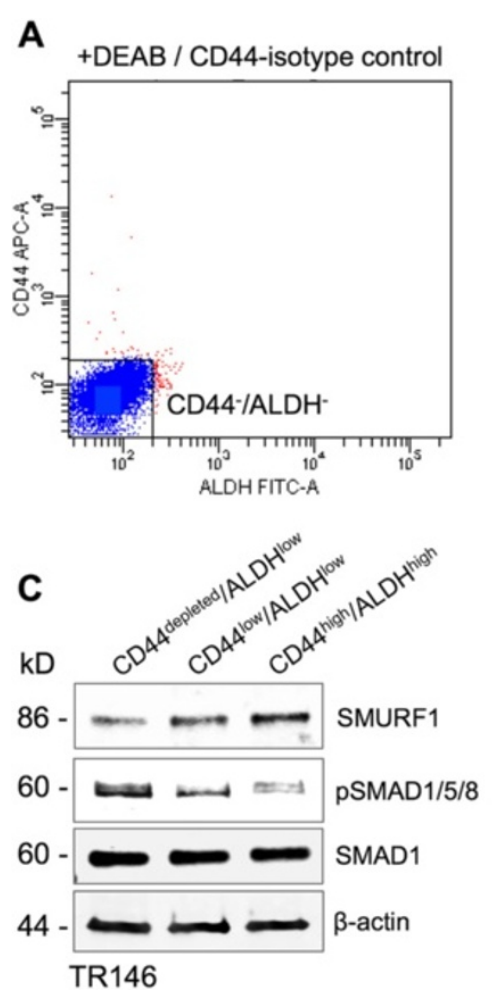

B
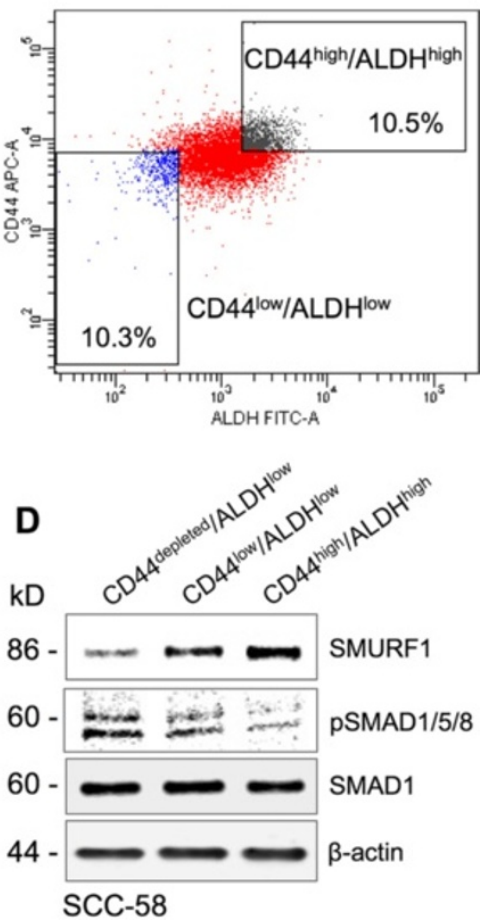

Figure 3 BMP signaling and SMURF1 are differentially regulated in CD44 $4^{\text {high }} / \mathrm{ALDH}^{\text {high }}$ sorted CSC-like populations. Representative FACS analyses of sorted cells are shown in A and B. (A) ALDEFLUOR stained cells in the presence of ALDH activity inhibitor DEAB and double-stained with APC-conjugated IgG isotype control. (B) Gating of CD44 low $/ A L D H^{\text {low }}$ and CD44 high/ALDH high populations. (C-D) Immunoblotting of SMURF1, pSMAD1/5/8, and SMAD1 (as a control for total SMAD protein) in the sorted TR146 (C) and SCC-58 (D) cells shown as representatives of at least three repeats from two independent cell sorting experiments. $\mathrm{CD} 44^{+}$cells in the CD44 ${ }^{\text {low }} / \mathrm{ALDH} \mathrm{H}^{\text {low }}$ sorted population were magnetically captured and removed to generate $\mathrm{CD} 44^{\text {depleted }} / \mathrm{ALDH}^{\text {low }}$ cells. $\beta$-actin was used as a total protein loading control for all samples.

culture conditions favoring sphere formation. Three different shRNA sequences were used to reduce SMURF1 expression, and the levels of SMURF1 mRNA were determined by qRT-PCR (Figure 5A). One sequence (shSMURF1-724) consistently reduced SMURF1 mRNA levels to the greatest extent in all cell lines. Decreased expression of SMURF1 was validated by immunoblotting (Figure 5B) in SDCs grown in the presence of FBS and Matrigel for 18-24 hours. Knockdown of SMURF1 led to partial reactivation of the BMP signaling pathway, indicated by the increase in pSMAD1/5/8 levels (Figure 5C). Taken together, our results show that SMURF1 regulates BMP signaling in CSC-like populations, which may have implications in maintaining the CSC-like phenotype.

\section{Inhibition of SMURF1 expression diminishes a subpopulation of CD44 ${ }^{\text {high }}$ cells}

SMAD1 has been shown to interact directly with the intracellular domain of CD44 [22,23,46], and the E3 ligase activity of SMURF1 targets SMAD proteins for degradation $[25,47,48]$. Thus, SMURF1 provides a functional link between CD44 and the BMP signaling cascade. Based on the relative increase in expression of SMURF1 in CD44 $4^{\text {high }}$ populations coupled with a decrease in BMP signaling, we hypothesized that SMURF1 plays a role in maintaining CSC-like cells within CD $44^{\text {high }}$ cell populations. Therefore, decreasing SMURF1 expression could potentially reduce the levels of CSC-like cells through BMP activation and differentiation. Knockdown of SMURF1 expression decreased the percentage of CD44 $4^{\text {high }}$ cells in SDC cultures grown for $4-11$ days (Figure $6 \mathrm{~A}$ and $\mathrm{B}$ ), suggesting the loss of a specific subpopulation of CSC-like cells. The decrease in the CD44 $4^{\text {high }}$ cells for TR146 SDCs following SMURF1 knockdown was highly reproducible in multiple, independent experiments $(n=5)$ but it was not statistically significant compared to the shNeg knockdown $(\mathrm{p}=0.138)$ or the parental $(\mathrm{p}=0.067)$ control cells (Figure $6 \mathrm{C})$. This was likely due to variation in the parental and shNeg SDC CD $44^{\text {high }}$ population enrichment from different experiments. Compared to the parental and shNeg controls, SMURF1 knockdown significantly reduced the number of CD44 ${ }^{\text {high }}$ cells in SCC-58 SDCs $(p=0.0092$ compared to shNeg, $\mathrm{p}=0.037$ compared to parental; $\mathrm{n}=7$ ) as shown in Figure 6D. We also noted that the CD44 ${ }^{\text {high }}$ population in the TR146 SDCs was less than the CD44 ${ }^{\text {high }}$ population in the SCC-58 SDCs, demonstrating the potential 


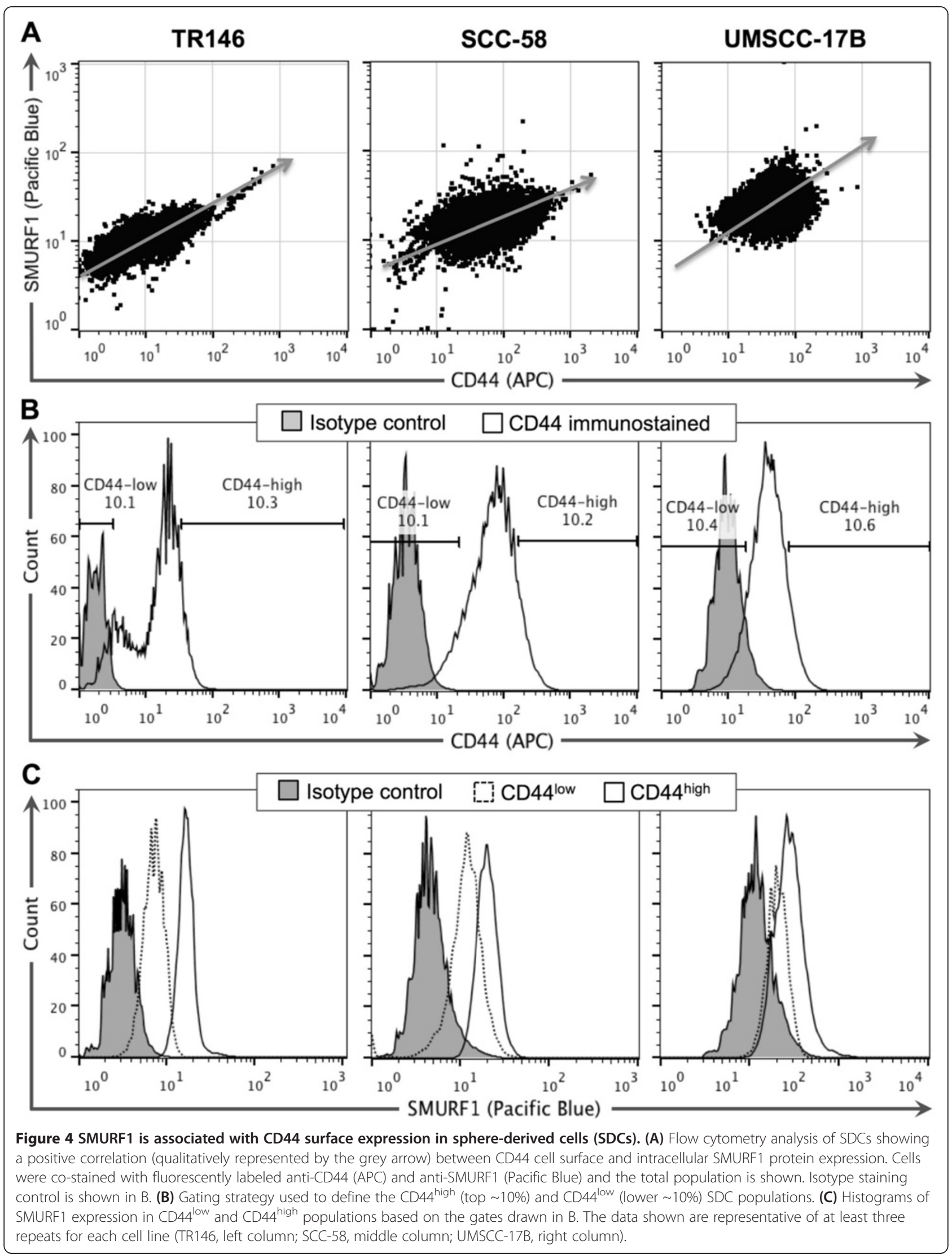




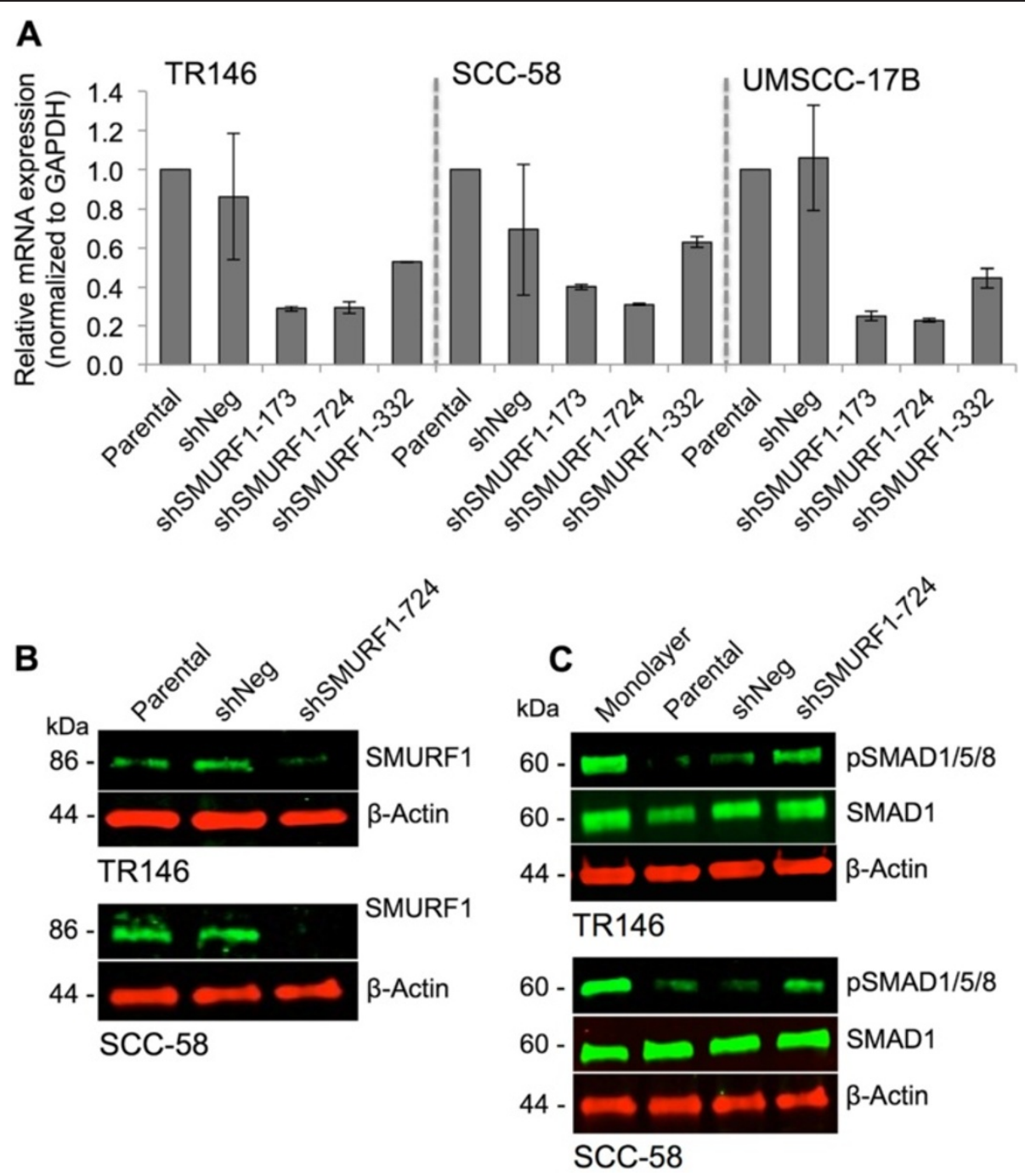

Figure 5 SMURF1 knockdown reactivates BMP signaling in SDCs. (A) SMURF1 knockdown screening by qRT-PCR in lentivirus transduced cells expressing negative knockdown shRNA control (shNeg) or one of three different shRNA constructs (shSMURF1-173, -724, and -332) targeting SMURF1 transcripts for silencing. Expression levels are relative to non-transduced parental control cells. Expression was normalized to the GAPDH housekeeping gene and presented as mean \pm SD. Screening was performed in monolayer cells in duplicate. (B) SMURF1 immunoblotting in SDCS expressing shSMURF1-724 shRNA gene silencing construct relative to shNeg and parental controls from two cell lines. (C) Immunoblotting of pSMAD1/5/8 in SDCs from two cell lines expressing shSMURF1-724 shRNA gene silencing construct relative to shNeg, parental, and monolayer cells. $\beta$-actin was used for a gel loading control. Data shown are representative of at least three independent experiments.

heterogeneity that may exist within HNSCC. Nonetheless, knockdown of SMURF1 greatly reduced the $\mathrm{CD} 44^{\text {high }}$ population in both cases. Co-staining of CD44 and SMURF1 in SDCs further verified that the reduction of a CD44 $4^{\text {high }}$ population correlated with the decreased expression of the SMURF1 protein (Additional file 4: Figure S4).

\section{Decreased expression of SMURF1 promotes}

differentiation and reduces tumorigenic capacity

To confirm the loss of a CD $44^{\text {high }}$ CSC-like population following SMURF1 knockdown, we tested whether these cells can be induced to undergo differentiation. To show differentiation capability, enriched CSC-like cells were cultured in adipogenesis differentiation medium for seven days. Lipid droplets were apparent in shSMURF1 SDCs after seven days in differentiating medium, but droplets were not present or not as prevalent in the parental and shNeg control SDCs or monolayer cells (Figure 7A). Both the parental and shNeg control SDCs showed similar background Oil Red $\mathrm{O}$ staining. Comparative analysis showed a significantly higher level (TR146, p $<0.0001$; SCC-58, p $<0.009$ ) of Oil Red O staining of lipid droplets in shSMURF1 SDCs than the shNeg or the parental SDCs (Figure 7B). These data suggest that sphere-enriched CSC-like cells have a progenitor-like phenotype that can 


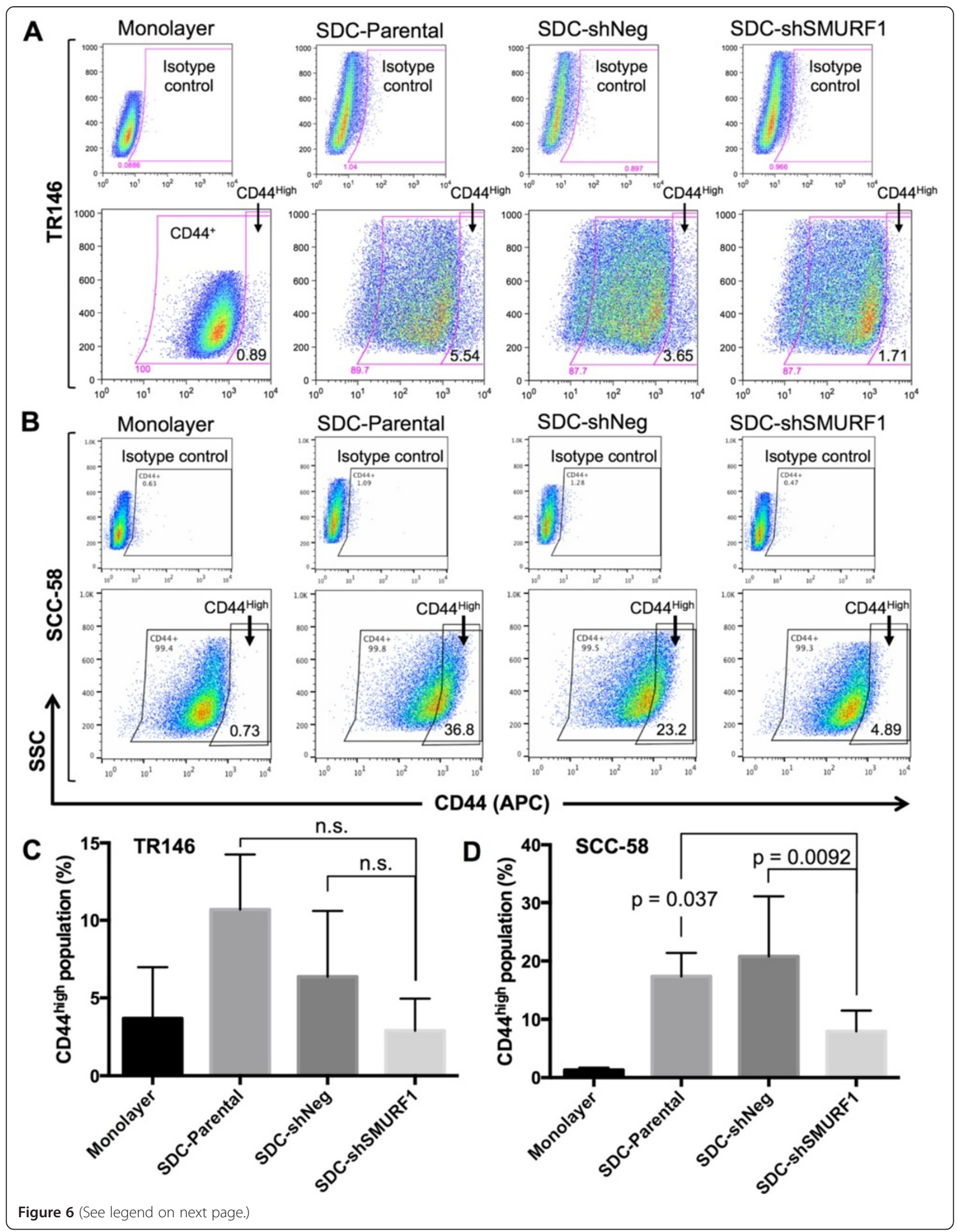


(See figure on previous page.)

Figure 6 SMURF1 inhibition reduces a CD44 ${ }^{\text {high }}$ cell population in SDCs. Representative flow cytometry analysis of CD44 ${ }^{\text {high }}$ cells in monolayer and in sphere-derived cells (SDCs) enriched from TR146 (A) and SCC-58 (B) sphere cultures are shown. A CD44 high population is reduced in SMURF1knockdown (shSMURF1) compared to shNeg and parental control SDCs after culturing in complete medium for 4 - 11 days. (C) Summary of flow cytometry analysis of CD44 ${ }^{\text {high }}$ TR146 SDCs shown in A $(n=5)$. (D) Summary of flow cytometry analysis of CD44 ${ }^{\text {high }}$ SCC -58 SDC s shown in B ( $n=7$ ). Data in $C$ and $D$ are presented as mean \pm SE for the indicated number of independent repeats. Statistical analysis was performed using two-tailed Student's t-test with equal variance. n.s. $=$ not significant $(p>0.05)$

be induced to differentiate by inhibiting SMURF1 and support the idea that SMURF1 plays a role in maintaining a CSC-like state.

Finally, we tested the ability of the sphere cell populations to form colonies from single-cell suspension in three-dimensional (3D), anchorage-independent medium supplemented with 20\% FBS. Clonogenicity in anchorageindependent growth medium is a method used to examine the tumor initiating capacity of cells. The control shNeg sphere cells formed colonies within 21 days, but shSMURF1 cells did not form colonies or formed a significantly lower number of colonies (TR146, $\mathrm{p}=0.03$; SCC-58, $\mathrm{p}=0.0002$; UMSCC-17B, $\mathrm{p}=0.0003$ ) (Figure $7 \mathrm{C}$ and $\mathrm{D}$ ). These results indicate that shSMURF1 sphere cells may have lost their capacity for anchorage-independent survival and selfrenewal, suggesting a loss in tumorigenic capacity.

\section{Discussion}

Subpopulations of tumor initiating cells from HNSCC are currently defined by their high expression of CD44 and BMI1 along with their high ALDH activity $[13,14,19,38,49,50]$. In addition, CD $44^{\text {high }} / \mathrm{ALDH}^{\text {high }}$ cells are highly tumorigenic and recapitulate heterogeneous tumors in mice. While the epithelial-to-mesenchymal transition regulator Snail was found to be key in maintaining the CSC properties in HNSCC through its regulation of ALDH expression [12], little else is known about how these populations are modulated or maintained. Here, we expand this line of investigation by utilizing CD $44^{\text {high }}$ expressing cells to represent CSC-like subpopulations from HNSCC cell lines combined with an analysis of the role of BMP signaling in regulating their maintenance. To do this, we enriched CSC-like cell populations, grown as non-adherent spheres, from three HNSCC cell lines. The sphere cells possessed CSC-like characteristics, including high expression of HNSCC CSC markers, CD44 and BMI1, resistance to the anti-cancer drug cisplatin, regeneration of spheres in suspension over multiple passages (self-renewal), and formation of visible colonies in three-dimensional culture assays. Sphere cells also showed increased expression of SMURF1 and inhibition of BMP signaling, indicating a potential regulatory mechanism for CSCs. The inverse relationship between SMURF1 and activation of the BMP signaling pathway was further confirmed in $\mathrm{ALDH}^{\text {high }}$ / $\mathrm{CD} 44^{\text {high }}$ populations, validating the use of our sphere cell culture system to test the hypothesis that BMP signaling regulates the fate of $\mathrm{HNSCC}$ CSCs.

BMP signaling is essential for cellular development, including induction of proliferation and differentiation, and has been shown to influence CSC populations in other cancers. In support of our hypothesis, activation of the BMP signaling cascade was shown to suppress CSC populations and metastatic potential of breast cancer [51], inhibit the tumorigenicity of CSCs in osteosarcoma and renal cell carcinoma [52,53], and reverse CSC-like traits in intestinal adenoma [54] and brain tumor-initiating cells [55]. Furthermore, inhibition of BMP signaling enhanced the CSC-like traits and metastatic potential of breast cancer cells [56]. While these studies confirm that the inhibition of BMP signaling plays a role in maintaining progenitor cells in a CSC-like state, contradictory reports show that activation by BMP2 enhances CSC-like populations in ovarian carcinoma [57], and BMP4 stimulates an epithelial-to-mesenchymal and a CSC-like phenotype in a squamous cell carcinoma cell line of the tongue [37]. Thus, the BMP signaling mechanisms utilized by various cancers to maintain their CSC populations may be tumor type specific. Alternatively, other mechanisms may come into play, which override the regulatory factors that contribute to inhibition or activation of BMP signaling. As a result, studies need to be undertaken to further define the role of BMP signaling in maintaining or regulating CSC-like cells.

To this end, we predicted that activation of the canonical BMP signaling pathway would counteract CSC phenotypes by signaling CSCs to undergo differentiation, resulting in the loss of self-renewal and the overall CSC population. In support of this idea, we determined that HNSCC sphere cells deactivate BMP signaling intracellularly by upregulating SMURF1, leading to decreased levels of pSMAD1/5/8 and ID1, the canonical BMP receptor signal transducer $[30,58,59]$ and BMP signaling target gene $[26,60]$, respectively. In both sphere cells and CD44 $4^{\text {high }}$ / $\mathrm{ALDH}^{\text {high }}$ sorted cells, pSMAD1/5/8 was decreased. Reduced levels of pSMAD1/5/8 and increased CD $44^{\text {high }}$ expression correlated strongly with increases in SMURF1 protein levels, indicating SMURF1 associated suppression of BMP signaling and maintenance of the CSC-like state. Knocking down SMURF1 partially restored BMP signaling and enhanced the induction of CSC-like cells to undergo differentiation as shown using an adipogenesis assay. The 


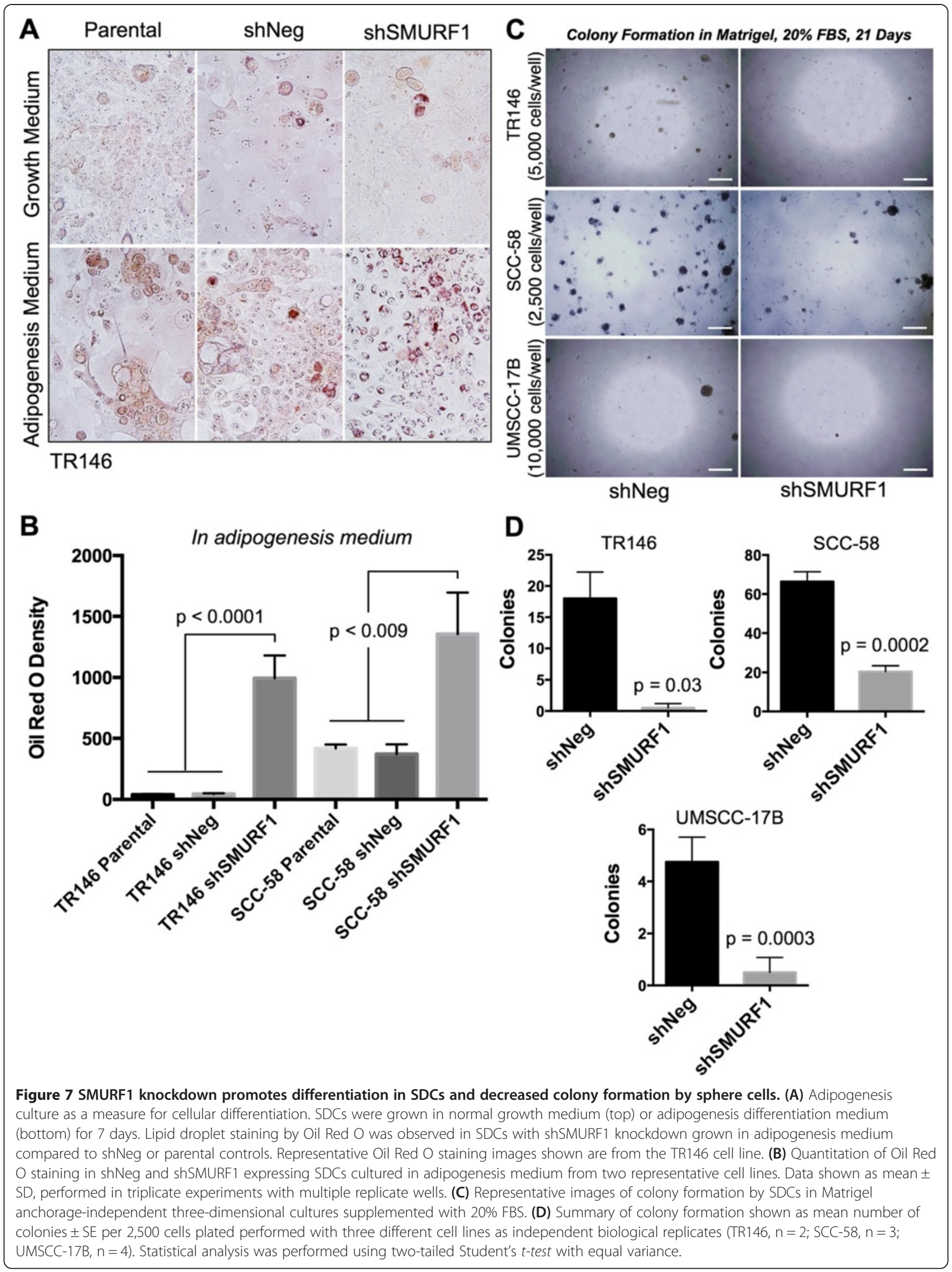


ability to differentiate suggests a progenitor-like phenotype of the sphere-enriched cells. In addition, reactivation of BMP signaling through suppression of SMURF1 reduced clonogenicity of CSC-like cells as shown by their inability to form colonies in anchorage-independent, 3D culture supplemented with FBS. Because differentiation and loss of clonogenicity occurred only after downregulation of SMURF1 and reactivation of BMP pathway, these results support our hypothesis that SMURF1 inhibition of BMP signaling supports the maintenance of CSC-like tumor population.

SMURF1 targets receptor-regulated SMAD proteins, primarily SMAD1, 5 and 8, in the BMP signaling pathway for degradation through association with inhibitory SMAD6/7, or I-SMADs [43-45]. Through I-SMADs, SMURF1 also can induce ubiquitination and degradation of BMP type I receptors, inhibiting the BMP signaling cascade [61]. While pSMAD1/5/8 levels were reduced overall in the presence of increased expression of SMURF1 in our studies, decreases in SMAD1 expression were not detected, a surprising result since SMURF1 targets SMADs for degradation. It also is possible that partial degradation of the targeted SMADs by SMURF1 may be occurring, and changes were below the detection limit of our assays. While other methods will need to be employed in order address this possibility, our observations suggest that regulation of BMP signaling by SMURF1 is likely to be more complex than previously thought, and it may explain why BMP signaling was only partially restored by reduced expression of SMURF1 in our assays.

To add to this complexity, previous studies in chondrocytes have demonstrated a direct interaction between CD44 and SMAD1 [22,23]. Here, CD44 acts as an intracellular scaffold protein to localize SMAD1 near BMP receptors, likely enhancing SMAD1 phosphorylation and activation [23]. Binding to CD44 in CSC-like cells may protect SMAD1 from degradation by SMURF1 but can also sequester the protein from phosphorylation and activation. How SMAD1 association with CD44 is regulated is not known. However, it is likely that the SMAD1/CD44 interaction provides a more precise and rapid response to BMPs as well as extracellular matrix proteins and conditions making the degradation of SMAD1 undesirable. It also is possible that partial release of SMAD1 from CD44 may occur upon loss of SMURF1 or limited activation of the BMP receptor. Thus, the role of SMAD1/CD44 signaling in the context of HNSCC CSCs warrants further investigation.

While our data are the first to implicate SMURF1 in the regulation of a CSC-like population, SMURF1 may play a similar role in other cancers. In human colorectal cancer, elevated expression of SMURF1 has been shown to correlate with cancer progression and prognosis [62]. In pancreatic cancer, SMURF1 amplification promotes tumor invasiveness [41], suggesting that SMURF1 might be used as an indicator of progression and/or prognosis for some cancers including those of the head and neck. While we have not yet undertaken such a study, the expression levels of SMURF1 in primary, recurrent, and drug resistant HNSCC tumors may be informative.

The recognition that other ubiquitin ligases play key roles in regulating both stem cells and CSC populations is becoming more widespread. The F-box protein Fbxw7, which is the substrate-recognition subunit of an SCF-type ubiquitin ligase complex, interacts with and mediates the ubiquitylation of c-Myc [63]. The ubiquitin-dependent degradation of c-Myc has been found to be essential for maintenance of the quiescence and reconstitution capacity of normal hematopoietic stem cells. For CSCs, Takeishi et al. [64] showed that Fbxw7 plays a pivotal role in maintenance of quiescence in leukemia initiating cells (LICs) in chronic myeloid leukemia by reducing the level of c-Myc. Abrogation of quiescence in LICs by Fbxw7 ablation increased LIC sensitivity to the tyrosine kinase inhibitor imatinib, and the combination of Fbxw7 ablation with imatinib treatment resulted in a greater depletion of LICs. Furthermore, King et al. [65] demonstrated that mutations in Fbxw7 specifically enhanced cancer-initiating cell activity in collaboration with Notch1 oncogenes in a model of T-cell acute lymphoblastic leukemia but spared normal hematopoietic stem cell function. Finally, the E3 ligase, Skp2, has been shown to be overexpressed in numerous human cancers and plays a critical role in cell-cycle progression, senescence, metabolism, cancer progression, and metastasis. By using a Skp2 inhibitor, Chan et al. showed Skp2 positively regulates CSC populations and self-renewal ability [66]. Notably, the Skp2 inhibitor exhibited potent antitumor activities in multiple animal models and cooperated with chemotherapeutic agents to reduce cancer cell survival. Based on these and other studies, ubiquitin ligases are promising targets for restricting cancer stem cell populations and cancer progression. In this regard, small molecule compounds that block the WW1 domain of Smurf1 from interacting with Smad1/5 have been reported in mouse cell lines [67], pointing to the feasibility of targeting human SMURF1 for therapeutic intervention.

\section{Conclusions}

Our findings suggest that SMURF1 inhibition of BMP signaling in CSC-like populations potentiates the longterm survival and maintenance of CSCs in head and neck cancer. Increased expression of SMURF1 and suppressed BMP signaling were found in sphere cell cultures and $\mathrm{CD} 44^{\text {high }} / \mathrm{ALDH}^{\text {high }}$ sorted populations. Restoration of BMP signaling by silencing SMURF1 reactivated BMP signaling, leading to increased cellular differentiation and reduction in the $\mathrm{CD} 44^{\text {high }}$ CSC phenotype. Our data strongly suggest a loss in self-renewal and tumorigenicity 
of CSC-like cells following SMURF1 knockdown. Thus, SMURF1 represents a potential drug target to inhibit the maintenance and progression of CSCs.

\section{Methods}

\section{Cell lines and cell culture conditions}

The HNSCC cell lines TR146, SCC-58, and UMSCC-17B were from the laboratory of Dr. Mark Herzberg, and their sources of origin and culture conditions were described previously [68]. Cells were cultured and maintained on standard tissue-culture treated flasks in Dulbecco's Modified Eagle Medium/Ham's F-12 50:50 mix (DMEM/F-12) supplemented with $10 \%$ fetal bovine serum (FBS) and $0.2 \%$ Primocin $^{\mathrm{Tx}}$ (InvivoGen, San Diego, CA, USA). The cells were maintained in $5 \% \mathrm{CO}_{2}$ at $37^{\circ} \mathrm{C}$. Each cell line was tested periodically for Mycoplasma expression by qPCR.

\section{Sphere cell culture}

Sphere cells were cultured as described previously but with the following modifications [10,34,35]. Monolayer cells were harvested by trypsinization when the flasks were approximately $75 \%$ confluent and cultured in DMEM/F-12 supplemented with $0.4 \%$ bovine serum albumin or BSA, $10 \mathrm{ng} / \mathrm{mL}$ b-FGF, $20 \mathrm{ng} / \mathrm{mL}$ EGF, and $5 \mu \mathrm{g} / \mathrm{mL}$ insulin. Cells were cultured as single-cell suspensions in ultralow attachment culture flasks (Corning Inc., Corning, NY) for 10 to 14 days. Spheres were collected every $3-4$ days by gravity to remove dead and non-sphere forming cells in the supernatant. The spheres were washed with PBS, and separated into single cell suspensions by incubating with $1 \mathrm{~mL}$ of $0.25 \%$ trypsin-EDTA for $2-4 \mathrm{~min}$ at room temperature. To generate sphere-derived cells (SDCs) for short-term proliferative growth studies, single cell suspensions of sphere cells were cultured on adherent tissue-culture treated flasks in complete medium supplemented with $75 \mu \mathrm{g} / \mathrm{mL}$ Matrigel $^{\mathrm{mm}}$ Basement Membrane Matrix Growth Factor Reduced (Stemcell Technologies Inc., Vancouver, BC, Canada).

\section{Cell sorting for CD44 $4^{\text {high }} /$ ALDH $^{\text {high }}$ cells}

Monolayer cultured cells $\left(15-20 \times 10^{6}\right)$ were harvested at approximately $70 \%$ confluency and stained for ALDH activity using an ALDEFLUOR ${ }^{\text {th }}$ Kit (Stemcell Technologies Inc.) based on the manufacturer's protocol. Following ALDEFLUOR staining, cells were centrifuged and resuspended in ice-cold staining buffer (ALDEFLUOR buffer containing 2\% FBS). Allophycocyanin (APC) conjugated rat monoclonal antibody against human $\mathrm{CD} 44$ (clone IM7; eBioscience Inc., San Diego, CA) was added at a 1:100 dilution and incubated on ice for $30 \mathrm{~min}$ in the dark. APC conjugated rat IgG2b isotype (eBioscience Inc.) was used as a negative staining control. Cells were washed with 10x volume of staining buffer and the cell number adjusted to $1 \times 10^{7}$ cells $/ \mathrm{mL}$ with staining buffer for sorting. Fluorescence activated cell sorting (FACS) was performed using a BD FACSAria II (BD Biosciences, San Jose, CA) equipped with a $100 \mu \mathrm{m}$ nozzle. CD $44^{\text {high }}$ / $\mathrm{ALDH}^{\text {high }}$ cells were sorted for by gating from the top $10 \%$ of double APC/FITC positive cells. CD $44^{\text {low }} / \mathrm{ALDH}^{\text {low } /-}$ cells were selected by gating for the lower $10-20 \%$ of the $\mathrm{APC}^{\text {low}} / \mathrm{FITC}^{\text {low/- }}$ cells. To further deplete CD44 positive cells, the sorted cells were expanded under standard monolayer culture conditions for four days, followed by CD44-positive cell depletion using an EasySep APC selection kit (Stemcell Technologies Inc.). Cultured CD44 ${ }^{\text {low } / ~}$ $\mathrm{ALDH}^{\text {low/- }}$ sorted cells were stained with APC conjugated anti-CD44 antibody, washed and magnetically captured and removed. Flow-through cell suspension was collected through magnetic separation several times, generating a population of $\mathrm{CD} 44^{\text {depleted }} / \mathrm{ALDH}^{\text {low }}$ cells.

\section{Gene expression analysis by qRT-PCR and PCR array}

Gene expression analysis by real-time quantitative RT-PCR (qRT-PCR) was performed using standard techniques. Total RNA extraction from cultured cells was performed using an RNeasy Mini Kit (Qiagen Inc., Valencia, CA) and analyzed using a Nanodrop spectrophotometer (Thermo Fisher Scientific Inc., Wilmington, DE). Samples were reverse transcribed using a SuperScript ${ }^{\circ}$ VILO cDNA synthesis kit (Life Technologies, Grand Island, NY). Realtime PCR was performed using FastStart Universal SYBR Green master mix (Roche Diagnostics GmbH, Mannheim, Germany) based on the manufacturer's protocol. Primers used for qRT-PCR were:

$\mathrm{CD} 44$

5' -CATCTACCCCAGCAACCCTA-3' (sense)

5' -ATCCCAGGTTTCTTGCCTCT-3' (antisense)

BMI1

5' -CAGCAATGACTGTGATGCACT-3' (sense)

5'-GGACCATTCCTTCTCCAGGT-3' (antisense)

$C D 24$

5'-ACCCACGCAGATTTATTCCA-3' (sense)

5' -ACCACGAAGAGACTGGCTGT-3' (antisense)

SMURF1

5'-CTGGATGCTTTTGGTCTGGT-3' (sense)

5' -CCTGATAGACGCGAACACAG-3' (antisense)

BMPER

5' -ACATCGACCTGGATGGCTAC-3' (sense)

5' -CCCTCCAAGATTCAGCAAAG-3' (antisense)

$B A M B I$

5' -ATCGCCACTCCAGCTACATC-3' (sense)

5'-TGTCGTGCTTGCAAGAGAGT-3' (antisense)

ID1

5' -CTCCAGCACGTCATCGACTA-3' (sense)

5' -CGCTTCAGCGACACAAGAT-3' (antisense)

ID2

5' -CCTCAACACGGATATCAGCA-3' (sense) 
5' -CCTCCTTGTGAAATGGTTGAA-3' (antisense)

BMP signaling pathway gene expression analysis was performed using a human TGF $\beta /$ BMP Signaling Pathway $\mathrm{RT}^{2}$ Profiler PCR Array System (Qiagen Inc.) with the provided $\mathrm{RT}^{2}$ First Strand Kit for cDNA synthesis, preloaded primer sets in 96-well format, and $\mathrm{RT}^{2}$ SYBR Green/ ROX PCR Master mix, according to manufacturer's protocol. PCR reactions were performed in Mastercycler ${ }^{\circ}$ ep realplex 2 (Eppendorf, Hauppauge, NY) real-time thermal cycler.

SMURF1 knockdown by lentivirus delivered shRNA system Human SMURF1 short hairpin RNA (shRNA) plasmids were purchased from Open Biosystems (Thermo Fisher Scientific Inc.). Three different SMURF1 targeting and silencing plasmids containing green fluorescence protein (GFP) and puromycin resistant genes (V2LHS_229724, V2LHS_203332, and V2LHS_363173) were supplied in E. coli competent cells. The cultures were expanded and the plasmids extracted using a QIAGEN Plasmid Midi kit (Qiagen Inc.). Extracted plasmids were then packaged into a Trans-Lentiviral ${ }^{\mathrm{Tm}}$ GIPZ lentivirus packaging system (Open Biosystems) and transfected into the TLA-HEK293T producer cell line according to the manufacturer's supplied protocol. Viral particle supernatants were collected at 48 and $72 \mathrm{~h}$ post-transfection and clarified by centrifugation. Clarified supernatants were filtered through a sterile $0.45 \mu \mathrm{m}$ low protein-binding filter and concentrated to $1 /$ $100^{\text {th }}$ of the original volume using Lenti-X Concentrator reagent (Clontech Laboratories, Inc., Mountain View, $\mathrm{CA})$. Concentrated viral particles were used to transduce cells in adherent monolayer culture at approximately $50 \%$ confluency in $1 \mathrm{~mL}$ complete medium supplemented with $8 \mu \mathrm{g} / \mathrm{mL}$ polybrene in 6-well plates overnight. After overnight incubation, viral particles were removed and the medium changed to normal growth conditions. Cells expressing either non-targeting random sequence shRNA (shNeg) control vector or SMURF1 targeting shRNA (shSMURF1) were monitored for GFP expression and further grown in selective medium containing $2 \mu \mathrm{g} / \mathrm{mL}$ puromycin for $72 \mathrm{~h}$ to eliminate non-transduced cells.

\section{Protein extraction}

Total protein was extracted from approximately $1 \times 10^{6}$ cells by incubating in RIPA lysis buffer (150 nM sodium chloride, $1.0 \%$ Triton X-100, $0.5 \%$ sodium deoxycholate, $0.1 \%$ sodium dodecyl sulphate, $50 \mathrm{nM}$ Tris, $\mathrm{pH}$ 8.0, 10\% glycerol) supplemented with fresh Halt ${ }^{\mathrm{tm}}$ protease and phosphatase inhibitor cocktail (Thermo Fisher Scientific Inc.) at 1:100 dilutions for $30 \mathrm{~min}$ on ice with periodic vortexing. Protein lysate supernatant was collected by centrifugation at $20,000 \times \mathrm{g}$ for $10 \mathrm{~min}$ at $4^{\circ} \mathrm{C}$ to remove insoluble materials, and the protein concentrations determined using a $\mathrm{BCA}^{\mathrm{m}}$ protein assay kit (Thermo Fisher Scientific Inc.).

\section{Immunoblotting analysis}

Immunoblotting was performed based on standard techniques as described previously [68]. Briefly, protein samples were boiled in 1X sample buffer and loaded onto $4-15 \%$ gradient SDS-polyacrylamide gel at $50 \mu \mathrm{g} /$ well for electrophoresis, transferred to nitrocellulose membrane, and blocked with $50 \%$ Odyssey $^{\circ}$ Blocking Buffer (LI-COR Biosciences, Lincoln, NE) diluted in TBST (20 mM Tris$\mathrm{HCl} \mathrm{pH} \mathrm{7.4,} 137 \mathrm{mM} \mathrm{NaCl}, 0.1 \%$ Tween-20). Rabbit antiSMURF1 primary polyclonal antibody (Cat\# AB10005; EMD Millipore, Billerica, MA) was added at a 1:300 dilution in blocking buffer and incubated for $1 \mathrm{~h}$ at room temperature. Rabbit anti-phospho-SMAD1 (Ser463/465)/ SMAD5 (Ser463/465)/SMAD8 (Ser426/428) or pSMAD1/ 5/8 (Cat\# 9511; Cell Signaling Technology, Danvers, MA) and rabbit anti-SMAD1 as a total SMAD protein control (Cat\# 6944; Cell Signaling Technology) were used at a 1:1000 dilution. Mouse anti- $\beta$-actin antibody (1:1000 dilution) was used as loading control. The membrane was washed three times with TBST, followed by incubation with LI-COR IRDye $800 \mathrm{CW}(780 \mathrm{~nm})$ donkey anti-rabbit and IRDye 680RD $(680 \mathrm{~nm})$ donkey anti-mouse infrared fluorescence dye conjugated secondary antibodies (LI-COR Biosciences) at a 1:10,000 dilution for 10 $15 \mathrm{~min}$ at room temperature using the SNAP i.d. Western Blotting System (EMD Millipore). After washing to remove excess secondary antibodies and Tween-20, the membranes were scanned and documented using an Odyssey infrared imaging system (LI-COR Biosciences) at $680 \mathrm{~nm}$ and $780 \mathrm{~nm}$ emission wavelengths.

\section{Immunostaining and flow cytometry}

Cell surface protein immunostaining was performed on single-cell suspensions of live cells. Approximately $1 \times 10^{6}$ cells were incubated in immunostaining buffer (PBS containing $2 \% \mathrm{FBS}$ and $2 \mathrm{mM}$ EDTA) for $10 \mathrm{~min}$ on ice followed by incubation with the fluorescence conjugated primary antibody on ice, for $30 \mathrm{~min}$, and in the dark. APC conjugated rat anti-human CD44 monoclonal antibody IgG2bk was used as described above at a 1:100 dilution to detect CD44-positive cells. An APC conjugated rat nonspecific IgG2b isotype was used as a negative staining control. For co-staining with mouse monoclonal antibody to detect intracellular SMURF1 protein, cells stained with CD44-APC antibody were fixed in 10\% phosphate buffered formalin for 30 min on ice, permeabilized with ice-cold $100 \%$ methanol for $30 \mathrm{~min}$ on ice or overnight at $4^{\circ} \mathrm{C}$, washed three times with staining buffer, and incubated with fluorescently labeled mouse anti-human SMURF1 monoclonal antibody (Sigma-Aldrich, Saint Louis, MO) at $1 \mu \mathrm{g}$ per $1 \times 10^{6}$ cells in PBS plus $1 \%$ BSA 
on ice for $30 \mathrm{~min}$. Anti-SMURF1 antibody was labeled with Zenon ${ }^{\circ}$ Pacific Blue fluorochrome for mouse IgG2a (Life Technologies). Mouse non-specific IgG2a isotype was labeled similarly and used as a negative staining control. The cells were washed, resuspended in staining buffer, and analyzed using a BD LSR II flow cytometer (BD Biosciences).

\section{Adipogenesis differentiation assay with Oil Red $\mathrm{O}$ staining} Adipogenesis assays were carried out using a StemPro ${ }^{\circ}$ Adipogenesis Differentiation kit (Life Technologies). Monolayer and sphere cells were cultured overnight in complete medium before switching to differentiation medium. Complete medium and sphere cell culture medium were used as negative controls for the monolayer and sphere cells, respectively. Cells were grown in differentiation or control medium for 7-14 days, with medium change every three days. To visualize intracellular microlipid droplets, growth media were carefully aspirated and cells were fixed in $4 \%$ paraformaldehyde for $30-40 \mathrm{~min}$ at room temperature. Following three washes with PBS and twice with water, Oil Red O solution (EMD Millipore) was added to cover the cells and incubated at room temperature for $50 \mathrm{~min}$. Cells were then washed three times with water, visualized under light microscopy, and imaged.

\section{Anchorage-independent colony formation}

Cells ( 5,000-10,000 per well) were grown as single-cell suspensions in complete medium containing $20 \%$ FBS and 50\% Matrigel $^{\mathrm{mm}}$ matrix on Ultra Low Cluster 96-well plates (Corning, Inc.). Embedded cells were incubated in $37^{\circ} \mathrm{C}, 5 \% \mathrm{CO}_{2}$ overnight to allow matrix polymerization before topping off each well with $200 \mu \mathrm{L}$ of complete medium. Cells were fed every seven days for a total of 21 days to allow colonies to form. Colonies were visualized by light microscopy using the lowest (4X) objective.

\section{Cytotoxicity, cell viability, and cisplatin resistance}

Cellular cytotoxicity assays were performed in tissueculture treated 96-well plates. Cells were seeded at 5,000 10,000 cells per well, overnight. Serial dilutions of cisplatin ( 0 to $10 \mu \mathrm{M}$ ) were added to the cells and incubated for $72 \mathrm{~h}$. Cell viability following cisplatin treatment was determined by CellTiter $96^{\circ}$ MTS assay (Promega Corp., Madison, WI). Cells were incubated with MTS solution for $3 \mathrm{~h}$ at $37^{\circ} \mathrm{C}, 5 \% \mathrm{CO}_{2}$, and the absorbance was measured at $490 \mathrm{~nm}$. Percent viability was calculated relative to untreated control.

\section{Statistics}

Statistical analysis was performed using unpaired twotailed Student's $t$-test with equal variance. Comparative analysis with $\mathrm{p}$-value $<0.05$ was considered significant.

\section{Additional files} Additional file 1: Figure S1. Representative flow cytometry analysis of
CD44 surface protein expression in (A) TR146, (B) SCC-58, and (C)
UMSCC-17B monolayer (top) and sphere (bottom) cells as summarized in
Figure 1C. Isotype controls are shown on the left in each panel.

Additional file 2: Figure S2. Sphere cells are more resistant to cisplatin than monolayer cells. Representative results from the SCC-58 and TR146 cell lines are shown. Cells were treated with cisplatin for $72 \mathrm{~h}$ and ratios of viable cells were measured by an MTS assay. Data are shown as mean \pm SD from at least three independent experiments.

Additional file 3: Figure S3. BMP ligand expression and secretion by sphere cells. (A) BMP2, 4, and 7 expression in sphere cells relative to monolayer cultures by qRT-PCR, shown as a representative of two repeats. (B) BMP2 secretion was higher in sphere cell cultures compared to their monolayer counterparts. Cell culture supernatants were collected at day 3 from the monolayer cells and at days 3, 7, and 14 from the sphere cells with a fresh medium change one day prior to sampling. The level of extracellular BMP2 production was measured using an ELISA and protein concentrations were normalized to the level of viable cells present based on MTS absorbance values. Data are presented as the concentration of BMP2 per MTS absorbance value, mean \pm SD, performed in duplicate.

Additional file 4: Figure S4. Representative flow cytometry analysis of SDCs double-stained with CD44 cell surface and intracellular SMURF1 proteins. The data shown are representative of at least three independent experiments.

\section{Competing interests}

The authors declare that they have no competing interests.

\section{Authors' contributions}

$A K, R G$, and EBD conceived the study and participated in its design. AK drafted the manuscript, performed the experiments, and analyzed, interpreted, and prepared data for publication. RG contributed to drafting the manuscript and interpreting data. EBD contributed to drafting the manuscript, interpreting data, and coordinating the study. All authors read and approved the final manuscript.

\section{Acknowledgements}

The authors acknowledge Nicholas Brady and Miranda Mulligan for their work on the CSC-like sphere cell enrichment and gene expression analyses. Some flow cytometry experiments were performed with the assistance of the Flow Cytometry Core Facility of the Masonic Cancer Center, a National Cancer Institute designated Comprehensive Cancer Center (supported in part by NIH P30 CA77598). This work was supported by the NIH R01-AR056642 (RG) and an Academic Health Center Seed (EBD) grant.

\section{Author details}

${ }^{1}$ Department of Veterinary Clinical Sciences, College of Veterinary Medicine, University of Minnesota, 1352 Boyd Avenue, Saint Paul, MN 55108, USA. ${ }^{2}$ Department of Diagnostic and Biological Sciences, School of Dentistry, University of Minnesota, 515 Delaware Street SE, Minneapolis, MN 55455, USA. ${ }^{3}$ Masonic Cancer Center, University of Minnesota, 425 East River Parkway, Minneapolis, MN 55455, USA.

Received: 17 June 2014 Accepted: 24 November 2014 Published: 3 December 2014

\section{References}

1. Siegel R, Naishadham D, Jemal A: Cancer statistics, 2013. CA Cancer J Clin 2013, 63:11-30.

2. Haddad RI, Shin DM: Recent advances in head and neck cancer. N Engl J Med 2008, 359:1143-1154.

3. Larson JT, Adams GL, Fattah HA: Survival statistics for multiple primaries in head and neck cancer. Otolaryngol Head Neck Surg 1990, 103:14-24.

4. Leemans $\mathrm{CR}$, Braakhuis BJ, Brakenhoff $\mathrm{RH}$ : The molecular biology of head and neck cancer. Nat Rev Cancer 2011, 11:9-22. 
5. Major AG, Pitty LP, Farah CS: Cancer stem cell markers in head and neck squamous cell carcinoma. Stem Cell Internat 2013, 2013:319489.

6. Henriksson E, Kjellen E, Baldetorp B, Bendahl PO, Borg A, Brun E, Mertens F, Ohlsson T, Rennstam K, Wennerberg J, Wahlberg P: Comparison of cisplatin sensitivity and the $18 \mathrm{~F}$ fluoro-2-deoxy 2 glucose uptake with proliferation parameters and gene expression in squamous cell carcinoma cell lines of the head and neck. J Exp Clin Canc Res 2009, 28:17.

7. Chu PY, Hu FW, Yu CC, Tsai LL, Yu CH, Wu BC, Chen YW, Huang PI, Lo WL: Epithelial-mesenchymal transition transcription factor ZEB1/ZEB2 co-expression predicts poor prognosis and maintains tumor-initiating properties in head and neck cancer. Oral Oncol 2013, 49:34-41.

8. Kokko LL, Hurme S, Maula SM, Alanen K, Grenman R, Kinnunen I, Ventela S: Significance of site-specific prognosis of cancer stem cell marker CD44 in head and neck squamous-cell carcinoma. Oral Oncol 2011, 47:510-516.

9. Prince ME, Sivanandan R, Kaczorowski A, Wolf GT, Kaplan MJ, Dalerba P, Weissman IL, Clarke MF, Ailles LE: Identification of a subpopulation of cells with cancer stem cell properties in head and neck squamous cell carcinoma. Proceed Nat Acad Sci U S A 2007, 104:973-978.

10. Okamoto A, Chikamatsu K, Sakakura K, Hatsushika K, Takahashi G, Masuyama $\mathrm{K}$ : Expansion and characterization of cancer stem-like cells in squamous cell carcinoma of the head and neck. Oral Oncol 2009, 45:633-639.

11. Davis SJ, Divi V, Owen JH, Bradford CR, Carey TE, Papagerakis S, Prince ME: Metastatic potential of cancer stem cells in head and neck squamous cell carcinoma. Arch Otolaryngol Head Neck Surg 2010, 136:1260-1266.

12. Chen YC, Chen YW, Hsu HS, Tseng LM, Huang PI, Lu KH, Chen DT, Tai LK, Yung MC, Chang SC, Ku HH, Chiou SH, Lo WL: Aldehyde dehydrogenase 1 is a putative marker for cancer stem cells in head and neck squamous cancer. Biochem Biophys Res Commun 2009, 385:307-313.

13. Clay MR, Tabor M, Owen JH, Carey TE, Bradford CR, Wolf GT, Wicha MS, Prince ME: Single-marker identification of head and neck squamous cell carcinoma cancer stem cells with aldehyde dehydrogenase. Head Neck 2010, 32:1195-1201.

14. Krishnamurthy S, Dong Z, Vodopyanov D, Imai A, Helman JI, Prince ME, Wicha MS, Nor JE: Endothelial cell-initiated signaling promotes the survival and self-renewal of cancer stem cells. Cancer Res 2010, 70:9969-9978.

15. Yu CC, Chen YW, Chiou GY, Tsai LL, Huang PI, Chang CY, Tseng LM, Chiou SH, Yen SH, Chou MY, Chu PY, Lo WL: MicroRNA let-7a represses chemoresistance and tumourigenicity in head and neck cancer via stem-like properties ablation. Oral Oncol 2011, 47:202-210.

16. Masui T, Ota I, Yook Jl, Mikami S, Yane K, Yamanaka T, Hosoi H: Snail-induced epithelial-mesenchymal transition promotes cancer stem cell-like phenotype in head and neck cancer cells. Int J Oncol 2014, 44:693-699.

17. Zhang Z, Filho MS, Nor JE: The biology of head and neck cancer stem cells. Oral Oncol 2012, 48:1-9.

18. Campos MS, Neiva KG, Meyers KA, Krishnamurthy S, Nor JE: Endothelial derived factors inhibit anoikis of head and neck cancer stem cells. Oral Oncol 2012, 48:26-32.

19. Chinn SB, Darr OA, Owen JH, Bellile E, McHugh JB, Spector ME, Papagerakis SM, Chepeha DB, Bradford CR, Carey TE, Prince ME: Cancer stem cells: Mediators of tumorigenesis and metastasis in head and neck squamous cell carcinoma. Head Neck 2014. doi:10.1002/hed.23600. [Epub ahead of print]

20. Chen YW, Chen KH, Huang PI, Chen YC, Chiou GY, Lo WL, Tseng LM, Hsu HS, Chang KW, Chiou SH: Cucurbitacin I suppressed stem-like property and enhanced radiation-induced apoptosis in head and neck squamous carcinoma-derived CD44(+)ALDH1(+) cells. Mol Canc Therapeut 2010, 9:2879-2892.

21. Lo WL, Chien Y, Chiou GY, Tseng LM, Hsu HS, Chang YL, Lu KH, Chien CS, Wang ML, Chen YW, Huang PI, Hu FW, Yu CC, Chu PY, Chiou SH: Nuclear localization signal-enhanced RNA interference of EZH2 and Oct4 in the eradication of head and neck squamous cell carcinoma-derived cancer stem cells. Biomaterials 2012, 33:3693-3709.

22. Peterson RS, Andhare RA, Rousche KT, Knudson W, Wang W, Grossfield JB, Thomas RO, Hollingsworth RE, Knudson CB: CD44 modulates Smad1 activation in the BMP-7 signaling pathway. I Cell Biol 2004, 166:1081-1091.

23. Luo N, Knudson W, Askew EB, Veluci R, Knudson CB: CD44 and Hyaluronan Promote the Bone Morphogenetic Protein 7 Signaling Response in Murine Chondrocytes. Arthritis Rheumatol 2014, 66:1547-1558.
24. Kobayashi A, Okuda H, Xing F, Pandey PR, Watabe M, Hirota S, Pai SK, Liu W, Fukuda K, Chambers C, Wilber A, Watabe K: Bone morphogenetic protein 7 in dormancy and metastasis of prostate cancer stem-like cells in bone. J Exp Med 2011, 208:2641-2655.

25. Sieber C, Kopf J, Hiepen C, Knaus P: Recent advances in BMP receptor signaling. Cytokine Growth Factor Rev 2009, 20:343-355.

26. Kudo TA, Kanetaka H, Watanabe A, Okumoto A, Asano M, Zhang Y, Zhao F, Kano M, Shimizu Y, Tamura S, Hayashi H: Investigating bone morphogenetic protein (BMP) signaling in a newly established human cell line expressing BMP receptor type II. Tohoku J Exp Med 2010, 222:121-129.

27. Sotillo Rodriguez JE, Mansky KC, Jensen ED, Carlson AE, Schwarz T, Pham L, MacKenzie B, Prasad H, Rohrer MD, Petryk A, Gopalakrishnan R: Enhanced osteoclastogenesis causes osteopenia in twisted gastrulation-deficient mice through increased BMP signaling. J Bone Mineral Res 2009, 24:1917-1926.

28. Nohe A, Hassel S, Ehrlich M, Neubauer F, Sebald W, Henis YI, Knaus P: The mode of bone morphogenetic protein (BMP) receptor oligomerization determines different BMP-2 signaling pathways. J Biol Chem 2002, 277:5330-5338.

29. Sun M, Forsman C, Sergi C, Gopalakrishnan R, O'Connor MB, Petryk A: The expression of twisted gastrulation in postnatal mouse brain and functional implications. Neuroscience 2010, 169:920-931.

30. Pham L, Beyer K, Jensen ED, Rodriguez JS, Davydova J, Yamamoto M, Petryk A, Gopalakrishnan R, Mansky KC: Bone morphogenetic protein 2 signaling in osteoclasts is negatively regulated by the BMP antagonist, twisted gastrulation. J Cell Biochem 2011, 112:793-803.

31. Rathinam C, Matesic LE, Flavell RA: The E3 ligase Itch is a negative regulator of the homeostasis and function of hematopoietic stem cells. Nat Immunol 2011, 12:399-407.

32. Rathinam C, Thien CB, Langdon WY, Gu H, Flavell RA: The E3 ubiquitin ligase $\mathrm{c}-\mathrm{Cb}$ restricts development and functions of hematopoietic stem cells. Genes Dev 2008, 22:992-997.

33. Jiang $X$, Xing H, Kim TM, Jung Y, Huang W, Yang HW, Song S, Park PJ, Carroll RS, Johnson MD: Numb regulates glioma stem cell fate and growth by altering epidermal growth factor receptor and Skp1-Cullin-F-box ubiquitin ligase activity. Stem Cells 2012, 30:1313-1326.

34. Chiou SH, Yu CC, Huang CY, Lin SC, Liu CJ, Tsai TH, Chou SH, Chien CS, $\mathrm{Ku} \mathrm{HH}$, Lo JF: Positive correlations of Oct-4 and Nanog in oral cancer stem-like cells and high-grade oral squamous cell carcinoma. Clin Cancer Res 2008, 14:4085-4095.

35. Lim YC, Oh SY, Cha YY, Kim SH, Jin X, Kim H: Cancer stem cell traits in squamospheres derived from primary head and neck squamous cell carcinomas. Oral Oncol 2011, 47:83-91.

36. Chen SF, Chang YC, Nieh S, Liu CL, Yang CY, Lin YS: Nonadhesive culture system as a model of rapid sphere formation with cancer stem cell properties. PLoS One 2012, 7:e31864.

37. Qiao B, Johnson NW, Chen X, Li R, Tao Q, Gao J: Disclosure of a stem cell phenotype in an oral squamous cell carcinoma cell line induced by BMP-4 via an epithelial-mesenchymal transition. Oncol Rep 2011, 26:455-461.

38. Sayed SI, Dwivedi RC, Katna R, Garg A, Pathak KA, Nutting CM, Rhys-Evans P, Harrington KJ, Kazi R: Implications of understanding cancer stem cell (CSC) biology in head and neck squamous cell cancer. Oral Oncol 2011, 47:237-243.

39. Chen C, Wei Y, Hummel M, Hoffmann TK, Gross M, Kaufmann AM, Albers AE: Evidence for epithelial-mesenchymal transition in cancer stem cells of head and neck squamous cell carcinoma. PLoS One 2011, 6:e16466.

40. Zhao L, Huang J, Guo R, Wang Y, Chen D, Xing L: Smurf1 inhibits mesenchymal stem cell proliferation and differentiation into osteoblasts through JunB degradation. J Bone Mineral Res 2010, 25:1246-1256.

41. Kwei KA, Shain AH, Bair R, Montgomery K, Karikari CA, van de Rijn M, Hidalgo M, Maitra A, Bashyam MD, Pollack JR: SMURF1 amplification promotes invasiveness in pancreatic cancer. PLoS One 2011, 6:e23924.

42. Chan MC, Nguyen PH, Davis BN, Ohoka N, Hayashi H, Du K, Lagna G, Hata $A$ : A novel regulatory mechanism of the bone morphogenetic protein (BMP) signaling pathway involving the carboxyl-terminal tail domain of BMP type II receptor. Mol Cell Biol 2007, 27:5776-5789.

43. Sapkota G, Alarcon C, Spagnoli FM, Brivanlou AH, Massague J: Balancing BMP signaling through integrated inputs into the Smad1 linker. Mol Cell 2007, 25:441-454. 
44. Horiki M, Imamura T, Okamoto M, Hayashi M, Murai J, Myoui A, Ochi T, Miyazono K, Yoshikawa H, Tsumaki N: Smad6/Smurf1 overexpression in cartilage delays chondrocyte hypertrophy and causes dwarfism with osteopenia. J Cell Biol 2004, 165:433-445.

45. Murakami G, Watabe T, Takaoka K, Miyazono K, Imamura T: Cooperative inhibition of bone morphogenetic protein signaling by Smurf1 and inhibitory Smads. Mol Biol Cell 2003, 14:2809-2817.

46. Miyazono K, Maeda S, Imamura T: BMP receptor signaling: transcriptional targets, regulation of signals, and signaling cross-talk. Cytokine Growth Factor Rev 2005, 16:251-263.

47. Sangadala S, Boden SD, Metpally RP, Reddy BV: Modeling and analysis of molecularinteraction between Smurf1-WW2 domain and various isoforms of LIM mineralization protein. Proteins 2007, 68:690-701.

48. Zhao M, Qiao M, Harris SE, Oyajobi BO, Mundy GR, Chen D: Smurf1 inhibits osteoblast differentiation and bone formation in vitro and in vivo. J Biol Chem 2004, 279:12854-12859.

49. Koukourakis MI, Giatromanolaki A, Tsakmaki V, Danielidis V, Sivridis E: Cancer stem cell phenotype relates to radio-chemotherapy outcome in locally advanced squamous cell head-neck cancer. Br J Cancer 2012, 106:846-853.

50. Nor C, Zhang Z, Warner KA, Bernardi L, Visioli F, Helman Jl, Roesler R, Nor JE: Cisplatin induces Bmi-1 and enhances the stem cell fraction in head and neck cancer. Neoplasia 2014, 16:137-146.

51. Buijs JT, van der Horst G, van den Hoogen C, Cheung H, de Rooij B, Kroon J, Petersen M, van Overveld PG, Pelger RC, van der Pluijm G: The BMP2/7 heterodimer inhibits the human breast cancer stem cell subpopulation and bone metastases formation. Oncogene 2012, 31:2164-2174.

52. Wang L, Park P, Zhang H, La Marca F, Claeson A, Valdivia J, Lin CY: BMP-2 inhibits the tumorigenicity of cancer stem cells in human osteosarcoma OS99-1 cell line. Cancer Biol Ther 2011, 11:457-463.

53. Wang L, Park P, Zhang H, La Marca F, Claeson A, Than K, Rahman S, Lin CY: BMP-2 inhibits tumor growth of human renal cell carcinoma and induces bone formation. Int J Cancer 2012, 131:1941-1950.

54. Farrall AL, Riemer $P$, Leushacke $M$, Sreekumar A, Grimm C, Herrmann BG, Morkel M: Wnt and BMP signals control intestinal adenoma cell fates. Int J Cancer 2012, 131:2242-2252.

55. Piccirillo SG, Reynolds BA, Zanetti N, Lamorte G, Binda E, Broggi G, Brem H, Olivi A, Dimeco F, Vescovi AL: Bone morphogenetic proteins inhibit the tumorigenic potential of human brain tumour-initiating cells. Nature 2006, 444:761-765.

56. Gao H, Chakraborty G, Lee-Lim AP, Mo Q, Decker M, Vonica A, Shen R, Brogi E, Brivanlou AH, Giancotti FG: The BMP inhibitor Coco reactivates breast cancer cells at lung metastatic sites. Cell 2012, 150:764-779.

57. McLean K, Gong Y, Choi Y, Deng N, Yang K, Bai S, Cabrera L, Keller E, McCauley L, Cho KR, Buckanovich RJ: Human ovarian carcinoma-associated mesenchymal stem cells regulate cancer stem cells and tumorigenesis via altered BMP production. J Clin Invest 2011, 121:3206-3219.

58. Forsman CL, Ng BC, Heinze RK, Kuo C, Sergi C, Gopalakrishnan R, Yee D, Graf D, Schwertfeger KL, Petryk A: BMP-binding protein twisted gastrulation is required in mammary gland epithelium for normal ductal elongation and myoepithelial compartmentalization. Dev Biol 2013, 373:95-106

59. Jensen ED, Pham L, Billington CJ Jr, Espe K, Carlson AE, Westendorf JJ, Petryk A, Gopalakrishnan R, Mansky K: Bone morphogenic protein 2 directly enhances differentiation of murine osteoclast precursors. J Cell Biochem 2010, 109:672-682

60. Kokabu S, Ohte S, Sasanuma H, Shin M, Yoneyama K, Murata E, Kanomata K, Nojima J, Ono Y, Yoda T, Fukuda T, Katagiri T: Suppression of BMP-Smad signaling axis-induced osteoblastic differentiation by small C-terminal domain phosphatase 1, a Smad phosphatase. Mol Endocrinol 2011, 25:474-481.

61. Murakami K, Mathew R, Huang J, Farahani R, Peng H, Olson SC, Etlinger JD: Smurf1 ubiquitin ligase causes downregulation of BMP receptors and is induced in monocrotaline and hypoxia models of pulmonary arterial hypertension. Exp Biol Med (Maywood) 2010, 235:805-813.

62. Xie P, Zhang M, He S, Lu K, Chen Y, Xing G, Lu Y, Liu P, Li Y, Wang S, Chai N, Wu J, Deng H, Wang HR, Cao Y, Zhao F, Cui Y, Wang J, He F, Zhang L: The covalent modifier Nedd8 is critical for the activation of Smurf1 ubiquitin ligase in tumorigenesis. Nat Commun 2014, 5:3733.

63. Nakayama Kl, Nakayama K: Ubiquitin ligases: cell-cycle control and cancer. Nat Rev Cancer 2006, 6:369-381.
64. Takeishi S, Matsumoto A, Onoyama I, Naka K, Hirao A, Nakayama KI: Ablation of Fbxw7 eliminates leukemia-initiating cells by preventing quiescence. Cancer Cell 2013, 23:347-361.

65. King B, Trimarchi T, Reavie L, Xu L, Mullenders J, Ntziachristos $P$, Aranda-Orgilles B, Perez-Garcia A, Shi J, Vakoc C, Sandy P, Shen SS, Ferrando A, Aifantis I: The ubiquitin ligase FBXW7 modulates leukemia-initiating cell activity by regulating MYC stability. Cell 2013, 153:1552-1566.

66. Chan CH, Morrow JK, Li CF, Gao Y, Jin G, Moten A, Stagg L, Ladbury JE, Cai Z, Xu D, Logothetis CJ, Hung MC, Zhang S, Lin HK: Pharmacological inactivation of Skp2 SCF ubiquitin ligase restricts cancer stem cell traits and cancer progression. Cell 2013, 154:556-568.

67. Cao Y, Wang C, Zhang X, Xing G, Lu K, Gu Y, He F, Zhang L: Selective Small Molecule Compounds Increase BMP-2 Responsiveness by Inhibiting Smurf1-mediated Smad1/5 Degradation. Sci Rep 2014, 4:4965.

68. Khammanivong A, Wang C, Sorenson BS, Ross KF, Herzberg MC: S100A8/A9 (Calprotectin) Negatively Regulates G2/M Cell Cycle Progression and Growth of Squamous Cell Carcinoma. PLoS One 2013, 8:e69395.

doi:10.1186/1476-4598-13-260

Cite this article as: Khammanivong et al:: SMURF1 silencing diminishes a CD44-high cancer stem cell-like population in head and neck squamous cell carcinoma. Molecular Cancer 2014 13:260

\section{Submit your next manuscript to BioMed Central and take full advantage of:}

- Convenient online submission

- Thorough peer review

- No space constraints or color figure charges

- Immediate publication on acceptance

- Inclusion in PubMed, CAS, Scopus and Google Scholar

- Research which is freely available for redistribution 